\section{Temas e enfoques contemporâneos nas Ciências Sociais e Humanas no Brasil: expressões e tendências refletidas no $\mathrm{V}$ congresso da área}

\author{
Contemporary themes and approaches in Social and \\ Human Sciences in Brazil: manifestations and \\ trends in the field's fifth national congress
}

\author{
${ }^{1}$ Instituto de Saúde Coletiva, \\ Universidade Federal da \\ Bahia, Salvador, Brasil. \\ Correspondência \\ L. A. B. Trad \\ Instituto de Saúde Coletiva, \\ Universidade Federal da \\ Bahia. \\ Rua Basílio da Gama s/n, \\ Salvador, $B A$ \\ 40110-040, Brasil. \\ trad@ufba.br
}


São Paulo em 2011, foco de análise deste artigo, a alusão ao "lugar...", refletiu o anseio de problematizar a questão do espaço que tem sido ocupado pelas Ciências Sociais e Humanas ao largo do processo de construção do campo da Saúde Coletiva no Brasil. O texto de apresentação do evento remarcava, em um duplo argumento, a abrangência e a importância das contribuições da área à saúde coletiva, e os desafios epistemológicos e políticos inerentes à sua incorporação em um contexto marcado pela diversidade conceitual, metodológica e organizacional, fonte permanente de tensionamentos entre os intelectuais e operadores desse campo.

Conforme assinalou Luz 3 (p. 306), o campo da saúde coletiva porta "uma estrutura discursiva semiaberta, com inclusão contínua de disciplinas oriundas de diferentes campos científicos" e tem experimentado ao longo das últimas décadas, uma complexificação de suas práticas e formas de intervenção social.

Não pretendo discutir ou problematizar neste artigo o amplo leque de questões mobilizadas nos três dias doV congresso. Proponho debruçarme sobre a produção científica do evento, procurando, oportunamente, traçar tendências e perspectivas. Compartilho do entendimento que o temário dos congressos (considerando aqui o conjunto de trabalhos veiculados) representa um indicativo de questões balizadoras da área, de tendências explicativas 4 , além de refletir modos de produção e dinâmica relacional entre os integrantes do campo.

Focalizarei, especificamente, os dados referentes aos Grupos Temáticos (GT), de cuja finalidade e dinâmica tratarei mais adiante. A principal estratégia metodológica adotada foi a análise documental, apoiada nas seguintes fontes: os anais do V Congresso de Ciências Sociais e Humanas em Saúde, detendo-se, particularmente, nos resumos dos trabalhos aprovados; o relatório final do evento.

Tendo em vista o tempo relativamente exíguo de que dispus para coleta e sistematização dos dados, adotei uma perspectiva mais panorâmica de análise. Oportunamente, assinalarei ao longo do texto aspectos mais específicos que considerei relevantes, procurando estabelecer um paralelo com os achados de estudos mais recentes de revisão sobre a produção em Ciências Sociais e Humanas no Brasil, realizadas por Canesqui 1,5 e Nunes 6, bem como os trabalhos de Gomes \& Goldenberg ${ }^{4}$ e Rezende et al. ${ }^{2}$, cujos objetos de análise, foram os congressos da área.

Avalio conveniente, por fim, situar o lugar de onde falo. Desde 2009, ocupo a função de coordenadora da Comissão Nacional de Ciências Sociais e Humanas da ABRASCO. Nesta posição, tive a oportunidade de assumir a tarefa de condução do último congresso da área e, portanto, tive acesso privilegiado ou facilitado às fontes de informações referidas a seguir na metodologia. Considero, por certo, que os argumentos e a perspectiva de análise expressa neste texto, refletem em certa medida este lugar de fala.

\section{Os Grupos Temáticos - recorrências, questões emergentes e ausência importantes}

O eixo central da programação científica do evento foram os GT, metodologia corrente em outros congressos da área de ciências sociais, que foi por primeira vez experimentada em congressos da ABRASCO. A expectativa, confirmada pela avaliação dos coordenadores de GT, era de que tal metodologia favorecesse o debate mais aprofundado em torno das temáticas e enfoques contemporâneos da área, privilegiando os trabalhos vinculados a grupos de pesquisas institucionalizados, mais ou menos consolidados (de modo a contemplar os emergentes). Pretendeu-se também estimular o intercâmbio entre grupos de pesquisa de diferentes regiões do país. Os critérios estabelecidos para a submissão de propostas de grupo temático procuraram favorecer o alcance desses objetivos.

Foram aprovados $21 \mathrm{GT}$, que acolheram um total de 1.482 trabalhos. Os títulos dos GT e a distribuição de trabalhos entre eles são descritos na Tabela 1. Antes de me deter sobre o perfil dos trabalhos veiculados nos GT, apontarei alguns aspectos relacionados com a conformação final dos grupos temáticos.

O recorte disciplinar foi posto em relevo em três o GT: 4, 9 e 20, destacando, respectivamente, a perspectiva histórica e sociológica. No caso do GT 6 , a ênfase recaiu sobre o recorte metodológico. No entanto, se considerarmos que a etnografia constitui uma abordagem vinculada à tradição antropológica, este GT pode ser contabilizado aqui.

Em qualquer caso, na conformação geral dos GT, predominou a lógica do recorte temático. O que é compreensível, tendo em vista que o viés interdisciplinar foi recomendado nas instruções ao público alvo. Caberia considerar também outros fatores, como o flexionamento das divisões disciplinares, outrora mais rígidas e, especialmente, à tendência a se definir temas mais específicos de pesquisa, construindo em torno deles, investigações de caráter interdisciplinar. Embora tal pretensão não extrapole muitas vezes o plano retórico.

Com respeito ao espectro de temas contemplados, chama especial atenção o número expres- 
Tabela 1

Distribuição de trabalhos aprovados por Grupo Temático (GT) no V Congresso Brasileiro de Ciências Sociais e Humanas em Saúde.

\begin{tabular}{|c|c|c|}
\hline \multicolumn{2}{|c|}{ Grupo Temático } & \multirow{2}{*}{$\begin{array}{c}\text { Trabalhos aprovados } \\
23\end{array}$} \\
\hline GT 1 & Aspectos Éticos das Pesquisas em Ciências Sociais e Humanas & \\
\hline GT 2 & A Política Brasileira de Atenção à Saúde Indígena: Percursos, Desafios e Perspectivas & 40 \\
\hline GT 3 & Análise de Narrativa e Experiência de Saúde, Adoecimento e Cuidado & 130 \\
\hline GT 4 & Ciências Sociais e Saúde em Perspectiva Histórica & 47 \\
\hline GT 5 & Corpo, Subjetividade e Saúde & 80 \\
\hline GT 6 & Etnografias nos Serviços de Saúde & 56 \\
\hline GT 7 & Família Contemporânea e Saúde: Sentidos, Relações e Práticas Sócio-Sanitárias & 62 \\
\hline GT 8 & Gênero, Sexualidade e Saúde & 56 \\
\hline GT 9 & História da Saúde e das Doenças & 31 \\
\hline GT 10 & Humanidades e Humanização em Saúde & 132 \\
\hline GT 11 & Integralidade, Mediações Sociais e Justiça na Demanda por Cuidado em Saúde & 137 \\
\hline GT 12 & Internet, Saúde e Sociedade & 58 \\
\hline GT 13 & Masculinidade, Saúde e Produção de Cuidado & 36 \\
\hline GT 14 & Movimentos Sociais e Educação Popular em Saúde & 156 \\
\hline GT 15 & Olhares Socioculturais Sobre as Enfermidades Crônicas & 39 \\
\hline GT 16 & Perspectivas Teóricas nos Estudos Sociais Sobre Ciência, Tecnologia e Inovação em Saúde & 35 \\
\hline GT 17 & Práticas de Saúde, AIDS, Gênero e Discriminação & 49 \\
\hline GT 18 & Racionalidades Médicas e Práticas em Saúde & 95 \\
\hline GT 19 & Saberes e Práticas Biomédicas e a Produção de Identidade & 49 \\
\hline GT 20 & Sociologia do Campo da Análise de Políticas Públicas e de Saúde no Brasil & 107 \\
\hline GT 21 & Violência de Gênero e Saúde & 64 \\
\hline Total & & 1.482 \\
\hline
\end{tabular}

sivo de GT que abordaram a temática de gênero. Em realidade, foram registradas seis propostas que traziam o gênero como tópico central. Esse resultado é compreensível se considerarmos que em meados da década de noventa, $29 \%$ dos profissionais da área de ciências sociais informaram trabalhar com gênero e saúde 6 .

A mesma pesquisa registrou $33,8 \%$ para racionalidade e práticas em medicina(s) e saúde, contra $46 \%$ em estudos sociais da ciência e da técnica 6; eixo que concentrou o maior percentual de respostas. Enquanto o primeiro tema se traduz claramente no GT 18, o segundo encontra-se diluído nos GT 16 (Perspectivas Teóricas nos Estudos Sociais sobre Ciência, Tecnologia e Inovação em Saúde) e 19 (Saberes e Práticas Biomédicas e a Produção de Identidade). Os respectivos enunciados diferem quanto às categorias de estudo postas em relevo.

O resgate da trajetória histórica das Ciências Sociais em Saúde, e seu processo de institucionalização na saúde coletiva brasileira, tema nuclear no V congresso da área, foi o foco do GT4. Quanto às questões da ética em pesquisa e movimentos sociais, que já figuravam desde o I encontro da área (1993) 4, foram contempladas pelos GT 1 e 14. Este último agregou também o tema da educação popular que se fez presente a partir do segundo congresso (1999), assim como e subjetividade e cultura, foco do GT 4. Outros objetos de estudo, como integralidade (GT 11), família contemporânea e saúde (GT 7) ou humanização em saúde (GT 10), despontaram no IV congresso (2005) e passaram a reverberar desde então.

O recorte étnico-racial se fez presente no GT 2 (A Política Brasileira de Atenção à Saúde Indígena: Percursos, Desafios e Perspectivas), prevalecendo no bojo dos trabalhos alocados aqui, o enfoque antropológico. Vale mencionar que a ausência de um GT que abordasse a saúde da população negra foi questionada por intermédio de $e$-mails dirigidos à organização do evento. Também foram recorrentes queixas relativas à não inclusão de um GT em saúde mental; uma temática que ocupou uma posição de destaque no bojo da produção científica das ciências sociais em saúde entre as décadas de 1990 e 20007.

Certamente, se considerarmos o temário global dos GT, outras lacunas importantes podem ser elencadas, a exemplo da violência (contem- 
plado apenas parcialmente no GT 21), tema que se destacou na produção da área entre 2000 e 2005 5. Uma produção que contribuiu para dar visibilidade ao problema da violência, além de remarcar a sua complexidade 8 . Os determinantes sociais em saúde ou Estado, sociedade e saúde, são temas a serem acrescidos no rol das ausências. Obstáculos relacionados com o tempo abreviado para a submissão de propostas de GT ou eventuais deficiências no processo de divulgação do evento poderiam figurar entre os fatores que influenciaram o perfil do temário dos GT, mas, decerto, não são razões suficientes para justificar as lacunas apontadas.

As redefinições em torno de escopo temático ou as novas ênfases em determinadas perspectivas teórico-metodológicas, refletem por sua vez a tendência à especialização das ciências sociais em saúde, sinalizada desde o final da década de 19907 e que implicou uma maior especificação de objetos de estudos e demarcação de perspectivas epistemológicas, teóricas etc. Deve ser considerado também o processo dinâmico de renovação de interesses e questões de estudo, tanto quanto os efeitos das interlocuções e parcerias entre grupos de pesquisa. Este aspecto pode ser apreendido na composição das coordenações dos grupos temáticos.

O pesquisador individual, figura tradicional no campo das ciências sociais, particularmente no caso da Antropologia ou da História, foi progressivamente cedendo lugar ao grupo de pesquisa. A década de 90 representou um momento de consolidação das pesquisas em ciências sociais, de inclusão de novas temáticas e conformação de interlocuções na pesquisas para além dos cursos de pós-graduação em saúde coletiva ${ }^{6}$. No cenário acadêmico atual, os grupos mais fechados e autorreferidos tendem a avançar na construção de interlocuções e parcerias como outros grupos, nacionais e internacionais.

\section{Tendências da produção: reiteração da dispersão temática e supremacia das microanálises}

Em termos de expressão quantitativa, é notória a evolução progressiva do número de participantes e de trabalhos científicos ao largo dos congressos de ciências sociais da ABRASCO 2. Convém ponderar, entretanto, que no caso do IV congresso (Salvador, 2007), a cifra expressiva de 3.168 trabalhos refletiu em grande medida a realização concomitante de três congressos, sendo dois deles internacionais. Como já foi referido, no $\mathrm{V}$ congresso foram aprovados 1.482 trabalhos, distribuídos nas modalidades oral, pôster (ou co- municação breve) e publicação nos anais, tendo sido estabelecidos tetos para aprovação nas duas primeiras modalidades.

Uma característica que se extrai de imediato na análise global dos trabalhos é a pulverização de temas ou questões abordadas. Uma diversificação que, se de uma parte pode refletir a complexidade envolvida na abordagem de temas cada vez mais "abrangenciáveis", de outra sugere uma excessiva especialização e fragmentação ${ }^{4}$.

Também salta aos olhos a prevalência de análises microssociais, apoiadas em métodos qualitativos (referidos em $68 \%$ dos trabalhos empíricos). Nesse sentido, revela-se especialmente oportuno estabelecer alguns paralelos entre o perfil da produção do $\mathrm{V}$ congresso e os resultados encontrados por Canesqui 5, ao perfilar a produção das ciências sociais e humanas em saúde no período de 1997 a 2007. Seu estudo levou em conta a publicação em periódicos de sete revistas brasileiras de Saúde Coletiva/Saúde Pública e se concentrou na análise dos resumos de 489 trabalhos que referiram adotar a pesquisa qualitativa.

Foi encontrada a seguinte distribuição temática: políticas e instituições de saúde $(32,5 \%)$, saúde e doença (18,5\%), gênero e saúde (16,5\%), violência e saúde (9\%), velhice e envelhecimento (7\%), recursos humanos, profissões e formação (7,5\%), estudos sociais das ciências e das técnicas (5\%) e educação e comunicação em saúde (4\%).

Na categoria "políticas e instituições de saúde", Canesqui 5 sublinhou os seguintes objetos de estudo: análises de implementação do SUS ou de políticas e programas específicos (focalizando gestão, modelo de atenção, processo de trabalho etc.), com destaque para o Programa Saúde da Família (PSF) (alvo privilegiado de pesquisas avaliativas), saúde do trabalhador ou saúde indígena; descentralização; relação público-privado; controle e participação social; reforma psiquiátrica, direito à saúde; temas de economia da saúde; saúde nas fronteiras. Foram considerados em separado os estudos que focalizaram "recursos humanos, profissões e formação" e "educação e comunicação em saúde". Com relação ao perfil do último segmento, foi salientada a incipiência de pesquisas que abordassem a internet e o seu papel na divulgação de informações em saúde. A produção veiculada no GT 12 (Internet, Saúde e Sociedade) indica que o tema já entrou na agenda de pesquisa da área.

Os grupos temáticos que concentraram os trabalhos em "políticas e instituições de saúde" ocuparam os primeiros postos em volume de trabalhos, o que resultou, em parte, da abrangência dos seus escopos e de eventuais deficiências no processo de avaliação (p.ex., aprovação de traba- 
lhos que não se enquadravam no temário do GT). Elenco, por ordem decrescente de concentração, os seguintes GT: 20 (Sociologia do Campo da Análise de Políticas Públicas e de Saúde no Brasil); 11 (Integralidade, Mediações Sociais e Justiça na Demanda por Cuidado em Saúde); 14 (Movimentos Sociais e Educação Popular em Saúde) - na taxonomia de Canesqui, o segundo foco seria alocado em "educação e comunicação em saúde"; 10 (Humanidades e Humanização em Saúde).

No caso do GT14 e do GT10, um percentual significativo de resumos descrevia relatos de experiências, sendo minoritários os trabalhos que reuniam resultados de pesquisa. O GT 20 reuniu um elenco bastante heterogêneo de questões (relação público-privado, reforma psiquiátrica, saúde do trabalhador, saúde ambiental, gestão de hospitais universitários, política de segurança alimentar, saúde nas fronteiras etc.), parte delas apontadas por Canesqui. No caso do GT11, destacaram-se: cuidado integral ou ética do cuidado, redes de saúde, matriciamento, direito à saúde, itinerários terapêuticos etc. Prevaleceram nesse segundo grupo temas de biopolítica e justiça social.

O destaque a determinadas políticas ou programas, dirigidos a grupos específicos, como indígenas ou família, se fez presente nos GT 2 e 7 , os quais privilegiaram em termos de questões e enfoques, dimensões ou perspectivas socioantropológicas, distinguindo-se assim das pesquisas avaliativas típicas. Contudo, sem dúvida, o GT 6 (Etnografias nos Serviços de Saúde) expressa de forma mais contundente a dita tendência. Vale notar que, em alguns resumos, caberia questionar se a referência ao uso da etnografia procedia. Um questionamento que pode ser extensível a certas pesquisas em saúde coletiva que referem à adoção do método etnográfico ${ }^{9}$.

Observou-se uma ausência ou presença discreta de trabalhos sobre temas típicos de Política, Planejamento e Gestão em Saúde, incluindo aqui "recursos humanos, profissões e formação" ou tópicos de "economia da saúde". Fato que pode ser atribuído à ocorrência do I Congresso Brasileiro de Política, Planejamento e Gestão em Saúde (Salvador, agosto de 2010), que absorveu a produção mais específica dessa área.

Com relação ao eixo saúde e doença, que alocou na pesquisa referida, trabalhos que abordaram a trajetória histórica de determinadas doença e os estudos de representações sociais ou da experiência da enfermidade, podemos considerar, para efeitos comparativos, a produção expressa nos seguintes GT: 3 (Análise de Narrativa e Experiência de Saúde, Adoecimento e Cuidado), 5 (Corpo, Subjetividade e Saúde), 9 (História da Saúde e das Doenças) e 15 (Olhares Socioculturais Sobre as Enfermidades Crônicas).
Dentre as tendências que podem ser extraídas, com base nas análise dos trabalhos vinculados aos GT acima, cabe ressaltar: (1) a categoria representação social, que ocupou cadeira cativa nos congressos de 1995 e 19994 e manteve-se ativa na produção da área 5, cede lugar para "narrativa de enfermidade" ou "sentidos/significados", apreendendo-se em alguns trabalhos o interesse em situar os discursos contemporâneos sobre saúdedoença-cuidado ou corpo; (2) experiências ou itinerários terapêuticos em torno das "enfermidade ou condições crônicas" (como o envelhecimento ou a dependência a psicoativos) ocuparam um espaço destacado no temário desses GT, e estiveram representados em vários outros; (3) reiterase o predomínio das abordagens compreensivas e fenomenológicas 5, confirmando-se ainda o incremento de estudos que investigam aspectos simbólicos da doença por intermédio das narrativas dos sujeitos adoecidos 6 .

Quanto aos estudos em gênero e saúde, o volume global de trabalhos no tema atesta a pujança da área, e a presença de quatro GT (Gênero, Sexualidade e Saúde; Masculinidade, Saúde e Produção de Cuidado; Práticas de Saúde, AIDS, Gênero e Discriminação, Violência de Gênero e Saúde) representando o eixo, corroboram a tendência de especialização desse subcampo de pesquisa.

O segmento estudos sociais das ciências e das técnicas também experimenta um claro processo de especialização, distinguindo-se na produção do $\mathrm{V}$ congresso três focos centrais: racionalidades e práticas de saúde, abrangendo a esfera da medicina institucionalizada e de outras arenas terapêuticas (GT 18); o discurso e a prática biomédica e a sua incidência na produção de subjetividades e identidades (GT 19); o complexo Ciência-Inovação-Tecnologia - CIT (GT 16).

Encerro o perfilhamento da produção dos grupos temáticos e faço uma referência especial ao GT 4 (Ciências Sociais e Saúde em Perspectiva Histórica). Os trabalhos apresentados cumpriram o papel de resgatar importantes contribuições das ciências sociais à produção de conhecimento em torno de fenômenos relevantes da saúde pública/ saúde coletiva, recuperando ciclos de pesquisa em determinados temas e resgatando a memória do patrimônio científico e intelectual da área.

Cumpre registrar, por fim, que em muitos grupos temáticos foi identificado um percentual significativo de trabalhos que derivavam de estudos sedimentados, oriundos de grupos de pesquisa institucionalizados. Sem dúvida, este é o indicador bastante positivo e denota o processo de amadurecimento do campo. Em contrapartida, foram identificados trabalhos que apresentavam inconsistências na descrição da abordagem teórica ou metodológica dos traba- 
lhos (a última não foi informada em cerca de 15\% dos resumos). Mantêm-se válidas, portanto, as críticas dos cientistas sociais que atuam na saúde coletiva frente ao uso inapropriado dos seus referenciais, produzindo distorções conceituais e metodológicas 10.

\section{Considerações finais}

O perfil da maioria dos grupos temáticos e o resultado global da produção do V Congresso de Ciências Sociais e Humanas em Saúde revelam que área reúne hoje um contingente substantivo de grupos de pesquisa consolidados ao lado de outros, que emergiram em centros acadêmicos dentro ou fora do eixo Rio-São Paulo. São indicadores de ampliação do grau de institucionalização e capilaridade regional da área.

Dentre os desafios, destaco, particularmente, o risco de atomização da pesquisa na área e a ne- cessidade de reequilibrar a relação macro-micro na definição de objetos e enfoques teórico-metodológicos. Conforme reportou Nunes 6 , por ocasião do I Encontro Brasileiro de Ciências Sociais em Saúde, em 1993, a constatação da crise dos modelos explicativos totalizantes, justificaram o apelo por investimentos em análises microssociais, abordando temas como subjetividade ou construção das identidades coletivas. Frente ao perfil atual da produção no campo, talvez seja hora de estimular um movimento inverso.

Também devem ser mantidas as preocupações com a produção efetiva de conhecimento novo ou original, comprometida em grande medida pelos atuais critérios de avaliação da produtividade científica 11. Reitero, por fim, o imperativo de implementação de estratégias de formação dos novos pesquisadores da área, favorecendo o manejo adequado dos aportes teóricos e metodológicos das ciências humanas e sociais na saúde coletiva.

\section{Resumo}

O V Congresso de Ciências Sociais e Humanas em Saúde da ABRASCO (São Paulo, Brasil, 2011) teve como tema central O Lugar das Ciências Sociais na Saúde Coletiva e propiciou um amplo processo de reflexão acerca da abrangência e importância das contribuições desta área ao campo da Saúde Coletiva. Este artigo discutirá a produção científica do evento, procurando, oportunamente, traçar tendências e perspectivas contemporâneas da área. No conjunto da programação científica, deter-me-ei na produção veiculada nos Grupos Temáticos (GT), metodologia que por primeira vez foi experimentada em congressos da ABRASCO, e que se constituiu no eixo central da programação científica do evento. A principal estratégia metodológica adotada foi a análise documental, apoiada nas seguintes fontes: os Anais do V Congresso de Ciências Sociais e Humanas em Saúde; o relatório final do evento. A análise comparada com os achados de revisão recente sobre a produção da área revelou permanência em termos de temas dominantes. Evidenciou-se também um incremento significativo das microanálises.

Publicações Científicas e Técnicas; Eventos Científicos e de Divulgação; Ciências Sociais 


\section{Agradecimentos}

À Daiane Celestino que colaborou no processo de sistematização dos resumos dos trabalhos aprovados nos 21 Grupos Temáticos (GT) e na elaboração da Tabela 1.

\section{Referências}

1. Canesqui AM. Ciências sociais e saúde no Brasil. Rio de Janeiro: Editora Hucitec; 2007.

2. Rezende OS, Ianni AMZ, Alves OSF, Barboza R. Uma contribuição para a história das Ciências Sociais na Saúde Coletiva - os Congressos Brasileiros de Ciências Sociais e Humanas em Saúde da Abrasco e suas produções científicas. Cad Saúde Colet (Rio J.) 2009; 17:603-26.

3. Luz MT. Complexidade do campo da saúde coletiva: multidisciplinaridade, interdisciplinaridade e transdisciplinaridade de saberes e práticas - análise sócio-histórica de uma trajetória paradigmática. Saúde Soc 2009; 18:304-11.

4. Gomes MHA, Goldenberg P. Interfaces e interlocuções: os congressos de ciências sociais em saúde. Ciênc Saúde Coletiva 2003; 8:251-64.

5. Canesqui AM. Produção científica das ciências sociais e humanas em saúde e alguns significados. Saúde Soc 2012; 21:15-23.
6. Nunes ED. A trajetória das ciências sociais em saúde na América Latina: revisão da produção científica. Rev Saúde Pública 2006; 40:64-72.

7. Canesqui AM. Ciências sociais e saúde no Brasil: três décadas de ensino e pesquisa. Ciênc Saúde Coletiva 1998; 3:131-68.

8. Schraiber LB, Oliveira AFPL, Couto MT. Violência e saúde: estudos científicos recentes. Rev Saúde Pública 2006; 40:112-20.

9. Trad LAB. Trabalho de campo, narrativa e produção de conhecimento na pesquisa etnográfica contemporânea: subsídios ao campo da saúde. Ciênc Saúde Coletiva 2012; 17:627-33.

10. Luz MT. Especificidade da contribuição dos saberes e práticas das Ciências Sociais e Humanas para a saúde. Saúde Soc 2011; 20:22-31.

11. Luz MT. Prometeu acorrentado: análise sociológica da categoria produtividade e as condições atuais da vida acadêmica. Physis (Rio J.) 2005; 15: 39-57.

Recebido em 22/Jul/2012

Aprovado em 17/Ago/2012 